TERRA. Revista de Desarrollo Local e-ISSN: 2386-9968

Número 7 (2020), 346-350

DOI 10.7203/terra.7.19355

IIDL - Instituto Interuniversitario de Desarrollo Local

\title{
Reseña. Gentrificación. Capitalismo cool, turismo y control del espacio urbano
}

\author{
Eugènia Benimeli Navarro \\ Licencidada en Sociología. Máster en Gestión y Promoción del Desarrollo Local \\ (Universidad de Valencia, España) \\ eubenimeli@gmail.com
}

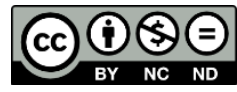

Esta obra se distribuye con la licencia Creative Commons

Reconocimiento-NoComercial-SinObraDerivada 4.0 Internacional 


\section{SECCIÓN RESEÑAS}

\section{Reseña. Gentrificación. Capitalismo cool, turismo y control del espacio urbano}

Resumen: Gentrificación. En las últimas décadas, muchos de nosotros habremos oído hablar sobre la gentrificación de nuestros barrios y ciudades. Pero, ¿sabemos realmente qué es y cómo funciona? En ocasiones, tal vez demasiadas, el término de gentrificación se ha querido entender como un proceso en el que barrios prácticamente abandonados a su suerte son regenerados o revitalizados. Qué hay detrás de todo este proceso es en parte lo que nos presenta el autor de este libro, utilizando conceptos relacionados con la gentrificación como la turistificación, la industria cultural y la creatividad, políticas neoliberales, negocio inmobiliario, etc.

Palabras clave: gentrificación, estructura social, espacio urbano, ciudades, población, capitalismo, turismo, territorio, políticas territoriales.

Recibido: 23 de diciembre de 2020

Devuelto para revisión: -

Aceptado: 24 de diciembre de 2020

Referencia / Citation:

Benimeli, E. (2020). Reseña. Gentrificación. Capitalismo cool, turismo y control del espacio urbano. TERRA. Revista de Desarrollo Local, (7), 346-350. DOI 10.7203/terra.7.19355 


\section{GENTRIFICACIÓN. CAPITALISMO COOL, TURISMO Y CONTROL DEL ESPACIO URBANO}

Madrid, Catarata, 2020, 96 páginas

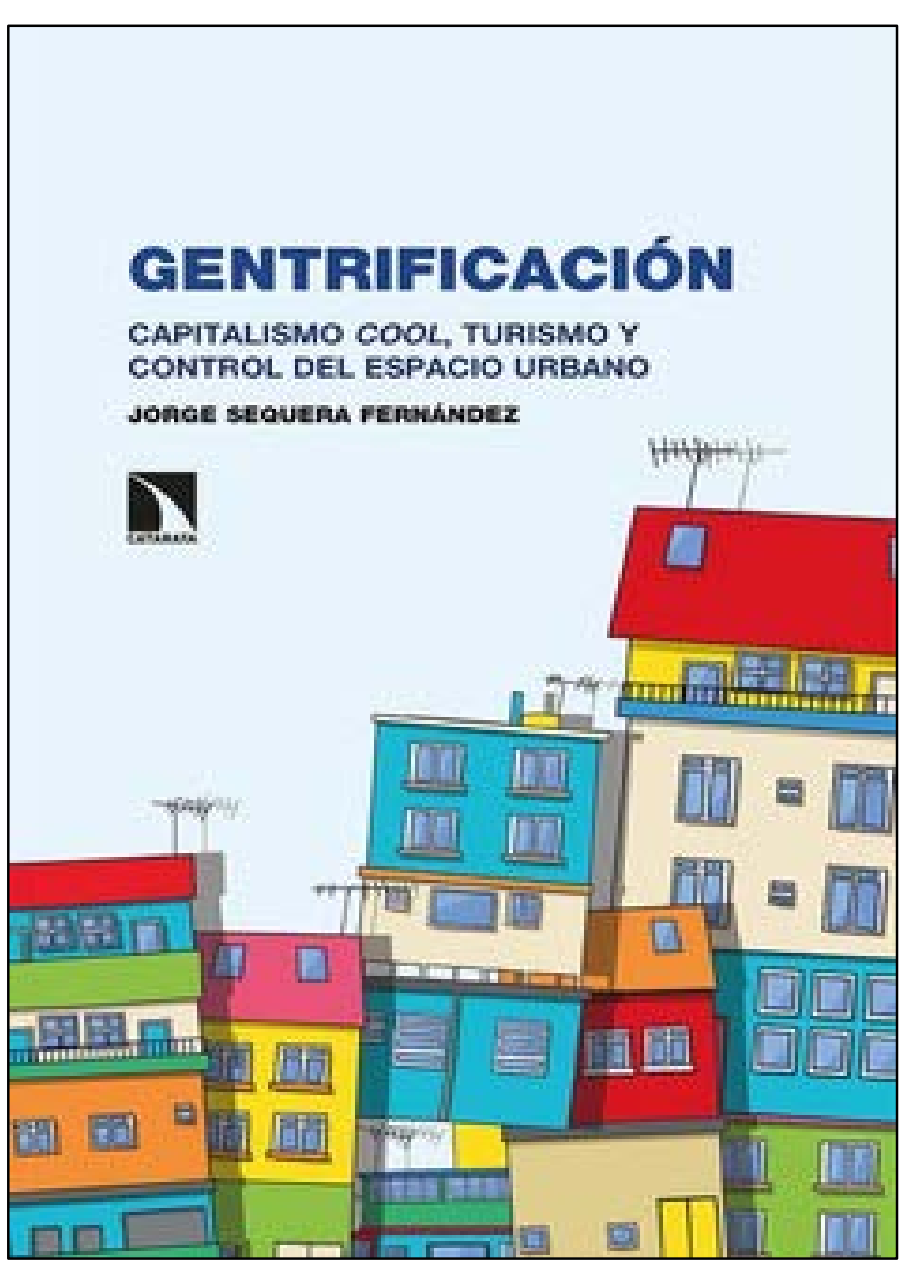

¿Qué es realmente la gentrificación? El autor nos define la gentrificación como 'la expulsión de gentes, prácticas y saberes de un territorio concreto a través de la reinversión de capital público y/o privado y la incorporación de una población con mayor capital económico o cultural', los cuales podrían ser considerados como deseables. Para entender un poco más sobre esta cuestión, el trabajo se ha dividido en 4 partes: ¿Qué es la gentrificación?; El mito de la clase creativa en la producción de la gentrificación; Segregación, expulsión y desplazamiento en el espacio público; y Turistificación, transformación urbana y nuevas precariedades.

En la primera parte, denominada '¿Qué es la gentrificación?' se aborda desde una perspectiva más teórica el propio término (Figura 1). Se podría definir la gentrificación como uno de los principales mecanismos contemporáneos de gestión urbana neoliberal, el cual se oculta tras la supuesta revitalización de barrios y ciudades. Pero para que pueda ponerse en marcha este mecanismo, es necesario que se cumplan diferentes premisas, entre las cuales se encuentra la inversión de capital público y privado, la entrada de grupos sociales con mayor capital económico y cultural, cambios en el paisaje urbano y el desplazamiento o expulsión de los grupos sociales con menores ingresos.

Uno de los ejemplos más claros para entender que es eso de la gentrificación lo encontramos en el proceso de desinversión de capital, produciéndose así una desvalorización y depreciación del capital invertido, hasta que se produzcan condiciones económicas objetivas que provoquen la revalorización. De esta forma, la gentrificación se produce cuando la diferencia es suficientemente amplia para que los promotores puedan comprar a precio más bajo y, cuando se pueda obtener un beneficio considerable, rehabilitar para vender el producto final por un precio de importante plusvalía. 
Figura 1. Índice de capítulos/contenidos

\begin{tabular}{|l|l|}
\hline CAPÍTULO l. ¿QUÉ ES LA GENTRIFICACIÓN? & $\mathbf{1 1}$ \\
\hline La inversión de capital público y privado & 13 \\
\hline La colonización de población con mayor capital económico y/o cultural & 16 \\
\hline Transformaciones del paisaje urbano y comercial & 19 \\
\hline Abandono, desplazamiento y segregación & 25 \\
\hline $\begin{array}{l}\text { CAPÍTULO 2. EL MITO DE LA CLASE CREATIVA EN LA PRODUCCIÓN DE LA } \\
\text { GENTRIFICACIÓN }\end{array}$ & $\mathbf{3 6}$ \\
\hline La fábula de la ciudad creativa & 38 \\
\hline La trama de la clase creativa & 40 \\
\hline Estilos de vida y consumo distintivo en los procesos de gentrificación & 45 \\
\hline CAPÍTULO 3. SEGREGACIÓN, EXPULSIÓN Y DESPLAZAMIENTO EN EL ESPACIO PÚBLICO & $\mathbf{5 7}$ \\
\hline La gubernamentalidad y el concepto de dispositivo & 58 \\
\hline El espacio público atravesado por las políticas neoliberales & 62 \\
\hline De la disciplina a la biopolítica: videovigilancia, burorrepresión y urbanismo preventivo & 65 \\
\hline $\begin{array}{l}\text { CAPÍTULO 4. TURISTIFICACIÓN, TRANSFORMACIÓN URBANA Y NUEVAS } \\
\text { PRECARIEDADES }\end{array}$ & $\mathbf{7 6}$ \\
\hline De los usos (y abusos) de la teoría de la gentrificación para explicar la turistificación urbana tras la crisis & 78 \\
\hline Entonces, ¿qué es la turistificación? & 83 \\
\hline Los impactos sociales de una ciudad airbnbizada & 86 \\
\hline ¿Y el turista? De lo exótico a lo cotidiano. Nadie quiere ser turista & 88 \\
\hline
\end{tabular}

Fuente: elaboración propia.

En la segunda parte del libro, 'El mito de la clase creativa en la producción de la gentrificación' se expone el concepto de las ciudades creativas y las clases sociales que la componen, y como afectan los distintos consumos y estilos de vida en la producción de la gentrificación. En este capítulo veremos cómo se interrelacionan entre sí estos conceptos, entendiendo que las ciudades creativas se componen de zonas urbanas donde se concentran actividades creativas, bienes y servicios de origen cultural, en las que se integran procesos productivos basados en la artesanía, el diseño y la arquitectura, la música, la literatura, la gastronomía, el cine, el arte digital, etc. En este sentido, la clase creativa es atraída a determinados espacios, configurándose como grupos de personas con intereses, comportamientos y formas de pensar comunes, determinados por la función económica de la economía creativa, los cuales contribuirían en la producción de la gentrificación.

Por ello, para comprender mejor los procesos de gentrificación y como contribuyen las clases creativas, es importante entender las prácticas culturales y de consumo, así como el tipo de relaciones sociales que se generan a partir de ellas, generando unas necesidades y demandas, las cuáles parece que tienden a ser cubiertas a través de las ciudades creativas, con las muchas consecuencias que esto supone, como la segregación espacial, elitismo, distinción y un largo etcétera.

En el tercer capítulo, ‘Segregación, expulsión y desplazamiento en el espacio público’ se habla de la gestión neoliberal de las políticas públicas y, en definitiva, del espacio público, a menudo disfrazado de progresismo político, social y económico, creando una serie de 
dinámicas sociales y espaciales en los distintos barrios de nuestras ciudades. Estas dinámicas darían como resultado diferentes procesos de tematización y espectacularización, promoviendo la segregación del espacio y el desplazamiento de determinados grupos sociales considerados menos deseables.

Algunas de las políticas públicas a las que se refiere el autor, las cuales contribuyen a la gentrificación de los espacios, se relacionan con conceptos como gubernamentalidad, disciplina, videovigilancia o burorrepresión. Lo público se convierte en lo cívico, y un montón de leyes que van normativizando el espacio público, con distintos tipos de colaboración, desde la policial hasta la vecinal. En este sentido, entrarían en juego nuevas formas de microvigilancia para cubrir aquellos espacios 'problemáticos', haciéndonos partícipes de su represión a través de la colaboración ciudadana para conseguir una ciudad más ordenada.

En el cuarto y último capítulo, 'Turistificación, transformación urbana y nuevas precariedades' el autor nos expone la relación existente entre los conceptos de gentrificación y turistificación que, aunque ambos se interrelacionan entre sí, no tienen el mismo significado. Parece que en los últimos años se ha tendido a sobrerelacionar estos conceptos debido a la contribución de la turistificación en la gentrificación, sobretodo a partir de la aparición de plataformas como Airbnb, acentuando este proceso en algunos espacios. A pesar de ello, no se puede explicar la turistificación solo en base a la gentrificación, y viceversa, pues la gentrificación, como veremos en este libro, responde a un proceso mucho más complejo. Si nos preguntamos entonces qué sería la turistificación, podríamos entender esta como la deriva del turismo hacia una estrategia política urbana, con el objetivo de transformar una ciudad para la mayor atracción de turistas.

Como vemos, la gentrificación es un proceso complejo interrelacionado con múltiples factores a los que deberemos atender si queremos dar respuesta a esta sociedad cambiante. Si el autor nos plantea el turismo como uno de los desafíos a la hora de repensar la ciudad y la segregación socioespacial, ahora también deberemos tener en cuenta otro desafío como lo es la actual pandemia que estamos atravesando.

Eugènia Benimeli Navarro Licenciada en Sociología. Máster en Gestión y Promoción del Desarrollo Local Universidad de Valencia 